\title{
Parental Stress in Cases of Children 'At Risk' for Specific Learning Disorder: A Pilot Study
}

Exarchou Paraskevi ${ }^{1}$, Simos Yannis ${ }^{2}$, Siafaka Vassiliki ${ }^{1}$ and Zakopoulou Victoria ${ }^{1^{*}}$

${ }^{1}$ Laboratory of New Approaches in Communication Disorders, Department of Speech and Language Therapy, School of Health Sciences, University of Ioannina, Greece

${ }^{2}$ Department of Physiology, Faculty of Medicine, School of Health Sciences, University of Ioannina, Greece

\section{Abstract}

Background: Neurodevelopmental Disorders do not only affect the child manifesting these disabilities, but they also have a significant impact on other family members. The dependence of these children on other family members for ongoing support can be a significant source of stress for parents.

Objectives: (i) to assess the stress of parents of children early diagnosed 'at risk' for Specific Learning Disorder and (ii) to test whether parental stress is correlated with specific conditions, such as sociodemographic characteristics as well as characteristics of the children's developmental history.

Methods: The sample was consisted of twenty-one parents whose children, 4-6 years old, were early diagnosed 'at risk' for Specific Learning Disorder. Participants were asked to complete a Parental Stress Index / Short Form (PSI-SF), a child's developmental history, and a form of sociodemographic characteristics.

Results: Findings revealed that parents experienced parental stress, which was associated with the disabilities of their children, while their occupational status is also related to the subscales of the Parental Stress/Short Form (PSI-SF). Statistical significance was found between the mean score of the subscales of the Parental Stress Index/ Short Form (PSI-SF) and characteristics of the developmental history of children diagnosed 'at risk' for Specific Learning Disorder, such as age of sitting, walking, saying the first words and phrases.

Conclusions: The findings of the current pilot study enhance the aspect that the earlier research is applied on the needs of children at "risk" for Specific Learning Disorder, parental discomfort, and dysfunctional parent-child interactions, the more appropriate is the treatment of both parental stress and the difficulties of children 'at risk' for Specific Learning Disorder.

\section{Introduction}

A multitude of definitions were used to clarify the nature of Learning Disabilities, with Kirk (1962) [1] first using the term of 'Learning Disabilities'. Although no definition is widely accepted for use in the international scientific community, the most accepted [2] is that supported by the National Joint Committee on Learning Disabilities.

'Specific Learning Disabilities' is a generic definition that refers to a heterogeneous group of disorders that manifest themselves with significant disabilities in using listening, speaking, reading, writing, reasoning or mathematical abilities. These disorders are intrinsic to the individual and are attributable to dysfunction of the central nervous system, and may even coexist throughout life. Problems with self-control, social interaction and social perception may be associated with specific learning disabilities. These problems, however, do not in themselves constitute specific learning disabilities [3]. Another definition that echoes modern scientific views on special learning disabilities is that developed by Kavale et al. (2009, p. 39-48) [4].

The term 'Specific Learning Disorder' (SLD) was firstly introduced in American Psychiatric Association's fifth edition of the Diagnostic and Statistical Manual of Mental Disorders (DSM-5TM). One of the six disorders comprised under the category of neurodevelopmental disorders, SLD refers to heterogeneous clusters of disorders that hinder smooth academic progress, at a rate of $2 \%$ to $3 \%$ of the student population. Lack of progress is evident in school performance, which remains below expectations from chronological and intellectual age, even when the child is enrolled in a personalized curriculum. The primary manifestation of lack of progress is a decline in one of the key skills (reading, writing, mathematics), which is not linked to inadequate educational, interpersonal, cultural - family and/or social - linguistic experiences [5].

The primary difference between competence and performance may be in the form of deficiencies in language ability (perceptual and / or expressive), cognitive function (problem solving, thinking ability, maturity), in neuropsychological processes (recruitment, attention, memory) or any combination of such deficiencies that are considered to result from dysfunctions of the central nervous system. It is worth noting that the neurodevelopmental disorders do not only affect the child manifesting these disabilities, but they also have a significant impact on the other family members [6]. According to family theories, family members interact in a transitional way, suggesting that children with neurodevelopmental disorders will have an impact on parents, the family system, and the siblings.

"Corresponding Author: Prof. Zakopoulou Victoria, Department of Speech and Language Therapy, University of Ioannina, $4^{\text {th }} \mathrm{km}$ of National Road of IoanninaAthens, 45500 Ioannina, Greece; E-mail: vzakop@uoi.gr

Citation: Paraskevi E, Yannis S, Vassiliki S, Victoria Z (2020) Parental Stress in Cases of Children 'At Risk' for Specific Learning Disorder: A Pilot Study. Int J Psychol Behav Anal 6: 170. doi: https://doi.org/10.15344/2455-3867/2020/170

Copyright: (C) 2020 Paraskevi et al. This is an open-access article distributed under the terms of the Creative Commons Attribution License, which permits unrestricted use, distribution, and reproduction in any medium, provided the original author and source are credited. 
Citation: Paraskevi E, Yannis S, Vassiliki S, Victoria Z (2020) Parental Stress in Cases of Children 'At Risk' for Specific Learning Disorder: A Pilot Study. Int J Psychol Behav Anal 6: 170. doi: https://doi.org/10.15344/2455-3867/2020/170

Page 2 of 6

It is well accepted that the parental care for any child can be stressful; however, parents generally respond well and adapt in order to maintain stability and manage life's challenges [7]. Conversely, the parents of a child with developmental disorders are adversely affected having as a result to experience greater instability and dysfunction than 'typical' families. Among the various examples of family research aimed at collecting the experience of parents who have children with developmental disorders, the most researched topic is parenting stress [8]. According to Abidin (1995) [9], it is defined as a chronic emotional phenomenon that the parent experiences because of his or her primary role and direct interaction with children. Parental stress is perceived as a psychological feeling in which the parent feels trapped by his or her parental responsibilities. In case the parent develops impaired parental abilities and anxieties about immediate or future failure in his or her role, transient stress can be converted to permanent parental stress.

The stress experienced by parents of child with learning disabilities is related to their difficulty in adapting to the child's needs, to the financial needs arising from the child's difficulty, to limited or no access to adequate information about the child's disabilities. At the same time, problems referring to the organization of time and the corresponding tensions along with the anticipation and procrastination the parents experience from the various services they need to request and receive assistance, are considered as reinforcing factors in the occurrence of stress between family members $[10,11]$

Although the role of the aforementioned factors in the levels of stress experienced by parents of children with learning disabilities is crucial, an equally important obstacle for these parents is the societal response to their children, as in some cases the social context fails to accept and integrate these children [10].

In addition to stress, parents often experience a host of other negative emotions, such as feelings of depression, isolation, despair, feelings of rejection, self-pity, and compassion towards the child, guilt, shame, stress, fear, overwhelming responsibilities, exclusion from the social environment, as well as dissatisfaction with their relationship and marriage [12]. As many researchers support, it is not only the financial demands of a child's parents with learning disabilities that are increasing, but also the physical and psychological needs of the child, as the child's needs are immediate, multilevel and increased [13]. As mentioned above, parents of these children have an increased risk of having high levels of stress [14]. Recent research suggests that the levels of stress experienced by parents of children with learning disabilities are increased compared to the levels of stress experienced by parents of children with no learning disabilities [15].

In light of the above theoretical aspects, the objectives of the present study were targeted to investigate whether: (i) parents of children early diagnosed 'at risk' for Specific Learning Disorder experience parental stress at such an early stage, in conjunction with their children's early onset of SLD and (ii) there are any possible correlations of parental stress with factors, such as the socio-demographic characteristics of the sample as well as the characteristics of their children's developmental history, through the following questions:

1. Do parents exhibit parental stress that is associated with the manifestation of their children's disabilities? If so, at what level?

2. Do the parents' socio-demographic characteristics impact the level of stress as it is recorded in the specific subscales of the Parental Stress Index / Short Form (PSI-SF)?
3. Are characteristics of their children's developmental history correlated with the scores in scales of PSI-SF of parents of children diagnosed 'at risk' for SLD?

\section{Material and Method}

\section{Participants}

The sample of this pilot study consisted of twenty-one Greek, monolingual parents whose children, aged from 5 to 6 years old, were referred to the Health and Care Center of the University Hospital, where children and adolescents are referred to for clinical investigation of neurodevelopmental disorders. All parents were asked to complete the Parental Stress Index / Short Form (PSI-SF) [9]. Interestingly, the applied questionnaires were answered by the mothers of the children, with the result that the whole sample consisted only of mothers. All children were examined through diagnostic tests for specific learning disorders, well standardized in Greek reality, for the onset of early signs of SLD, while children with intellectual disabilities, Autistic Spectrum Disorder (ASD), Specific Language Impairment (SLI), and any neurological disorder were excluded. 20children diagnosed at risk' for SLD, followed early forms of intervention, well adapted to their weaknesses and strengths [16].

All parents voluntarily participated and signed a written informed consent form. This pilot study was conducted in accordance with the Ethical Standards as set out in the Declaration of the Helsinki World Medical Association (2002).

It is worth noting that due to the prerequisites of the exclusive disorders, the age of the children and the obligation of parental consent, the final sample size was quite limited. However, it could be considered [17] adequate for this pilot study, given that there are no relevant studies that test parental stress in cases of early diagnosis of SLD.

\section{Measures}

The main measure used was the Parental Stress Index / Short Form (PSI-SF) [9], which is a brief version of the Parental Stress Index, a widely used and well-documented parental stress measurement tool. It estimates the difficulties in the relationship between children and parents based on the aspect that parent-child stress is the result of the characteristics of the child, the parent, and the circumstances surrounding this relationship.

The questionnaire is designed to detect potential risks to the child's normal development as well as to observe problems in the parenting role [18]. It consists of 36 questions and the answers are given with a 5-point Likert scale totally disagree (1), disagree (2), neutral (3), agree (4) and, finally, totally agree (5). The total mean score ranges from 36 to 180 and high scores indicate greater parental stress. Studies on the validity and reliability of the tool give Cronbach's alpha $=0.91$ for the overall stress score, and a reliability index of one to three months $r=$ $0.84[19,20]$. The five subscales of the inventory of parental stress are [21] as follows:

1. Defensive Response (DR). It indicates a possible bias and the score ranges from 12 to 60 .

2. Parent Distress Score - (PD) [22]. It measures the stress parents feel about raising their child in relation to other personal stressful situations and has a failure rating of 36 . 
Citation: Paraskevi E, Yannis S, Vassiliki S, Victoria Z (2020) Parental Stress in Cases of Children 'At Risk' for Specific Learning Disorder: A Pilot Study. Int J Psychol Behav Anal 6: 170. doi: https://doi.org/10.15344/2455-3867/2020/170

Page 3 of 6

3. Parent Child Dysfunctional Interaction Score (RCDI). Rating Scale for Dysfunctional Interaction. It focuses on the child's perception of whether he/she meets the parents' expectations and has a failure rating of 27 .

4. Difficult Child Score (DC). It represents the behaviors in which the child is often engaged that make it easier or more difficult to raise a child and has a failure rating of 36 .

5. Total Stress Score (PSI). The score ranges from 36 to 180 [23].

\section{Statistical analysis}

Data were described using frequencies and percentages for the case of categorical variables, while for the case of continuous, the mean and standard deviation were used. The Pearson linear correlation coefficient was used for the correlations, following the Shapiro Wilk test for the symmetry of the correlated dimensions. One-way ANOVA variance analysis was used to determine whether a relationship exists between dependent and independent variables.

The significance level ( $p$ value) was set at $\mathrm{a}=.005, \mathrm{a}=.01, \mathrm{a}=.001(p$ $<.005, p<.05, p<.01, p<.001)$ and analyzed with SPSSv 22.0 software.

\section{Results}

The present study included twenty-one $(\mathrm{N}=21)$ mothers of children, 4 -6 years old, who were tested for early diagnosis of SLD. Regarding marital status, nineteen $(\mathrm{N}=19)$ mothers were married $(90.5 \%)$ and two $(\mathrm{N}=2)$ were divorced (9.5\%). In terms of their educational level, most of them $(\mathrm{N}=13,61.9 \%)$ were university graduates $(61.9 \%)$ Finally, the main types of occupations were private employees (33.3\%) and unemployed $(28.3 \%)$ whereas there were also civil servants (19.0\%), freelancers (14.3\%), and farmers (4.8\%) (Table 1).

Testing the parental stress, the data analysis of the Parental Stress Index-Short Form (PSI-SF) estimated the scoresinboth subscales of the questionnaire and the mothers' total parental stress. As it is shown in Table 2, the highest values are recorded in the Total Stress scale (71.6), followed by the subscales of Difficult Child (DC) (26.1) and Parental Distress (PD) (24.7).

\begin{tabular}{|c|c|c|}
\hline & $\mathrm{N}$ & $\%$ \\
\hline \multicolumn{3}{|l|}{ Marital status } \\
\hline Married & 19 & 90.5 \\
\hline Divorced & 2 & 9.5 \\
\hline \multicolumn{3}{|l|}{ Educational level } \\
\hline Elementary school & 1 & 4.8 \\
\hline Secondary school & 1 & 4.8 \\
\hline High school & 6 & 28.6 \\
\hline University & 13 & 61.9 \\
\hline \multicolumn{3}{|l|}{ Occupational status } \\
\hline Unemployed & 6 & 28.6 \\
\hline Farmer & 1 & 4.8 \\
\hline Freelancer & 3 & 14.3 \\
\hline Private employee & 7 & 33.3 \\
\hline Civil servant & 4 & 19.0 \\
\hline
\end{tabular}

Int J Psychol Behav Anal

ISSN: 2456-3501

IJPBA, an open access journal

Volume 6. 2020. 170
Table 2: Mean score of subscales and total stress score of the PSI-SF of parents of children diagnosed 'at risk' for SLD.

Note: $\mathrm{SD}=$ Standard Deviation; $\mathrm{DR}=$ Defensive Responding Score; $\mathrm{D}=$ Parental Distress Score; PCDI $=$ Parent-Child Dysfunctional Interaction Score; $\mathrm{DC}=$ Difficult Child Score

Aiming to investigate whether parental stress is unfenced by sociodemographic characteristics, using the analysis of variance of ANOVA (Table 3) we compared the relationship between three demographic characteristics (marital status, educational level, and occupational status) and the total mean score of the PSI-SF. Occupational status was observed to be highly interrelated with the parents' total stress score $(\mathrm{p}=.006)$. However, due to the small sample, no further analysis was implied in order to justify exactly which categories of occupational status impact the parental stress.

\begin{tabular}{|l|l|l|l|l|l|l|}
\hline \multicolumn{7}{|c|}{ Maritalstatus } \\
\hline \multicolumn{2}{|c|}{} & SS & df & $\begin{array}{l}\text { Mean } \\
\text { Square }\end{array}$ & F & Sig. \\
\hline \multirow{7}{*}{ PSI-SF } & BetweenGroups & 2.193 & 2 & 2.193 & 1.057 & .317 \\
\cline { 2 - 8 } & Within Groups & 39.424 & 19 & 2.075 & & \\
\cline { 2 - 8 } & Total & 41.617 & 21 & & & \\
\hline \multicolumn{7}{|c|}{ Occupational level } \\
\hline \multirow{2}{*}{ PSI-SF } & Between Groups & 3.117 & 4 & 1.039 & .459 & .715 \\
\hline & Within Groups & 38.500 & 17 & 2.265 & & \\
\cline { 2 - 8 } & Total & 41.617 & 21 & & & \\
\hline \multirow{2}{*}{ PSI-SF } & Between Groups & 23.970 & 5 & 5.993 & 5.434 & .006 \\
\hline & Within Groups & 17.646 & 16 & 1.103 & & \\
\hline & Total & 41.617 & 21 & & & \\
\hline
\end{tabular}

Table 3: Variance analysis between the total mean score of the PSISF and socio-demographic characteristics of parents of children diagnosed 'at risk' for SLD.

Understanding the possible role of the child's development in the parents' stress, the possible correlation between specific characteristics (motor and language development) of the child's developmental history and the scores on the subscales of the PSI-SF were tested.

Interestingly, multiple statistically significant correlations were recorded between the scores of parents of children diagnosed 'at risk' for SLD in scales of PSI-SF and characteristics (measured in months) of their children's developmental history, as follows (see Table 4):

1. Multiple inter correlations were observed between the age of acquiring the skills of sitting, walking, babbling, and saying the first words (all variables were measured in months) [in a range of statistical significance between $p=.000-p=.013$ ].

2. Similarly, the above skills were highly correlated with all PSISF subscales and the total stress score (in a range of statistical significance $p=.000-p=.038$ ). 
Citation: Paraskevi E, Yannis S, Vassiliki S, Victoria Z (2020) Parental Stress in Cases of Children 'At Risk' for Specific Learning Disorder: A Pilot Study. Int J

\begin{tabular}{|c|c|c|c|c|c|c|c|c|c|c|c|c|c|c|c|c|c|c|c|c|c|c|c|}
\hline 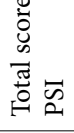 & & & & & & & & 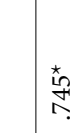 & $\begin{array}{l}m \\
?\end{array}$ & 잉 & 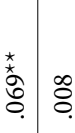 & $=$ & $\mid$ & 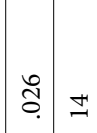 & 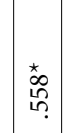 & \begin{tabular}{|l|l} 
& $\infty$ \\
\hdashline & 0
\end{tabular} & 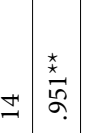 & ¿. & 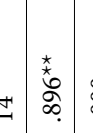 & 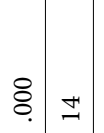 & & & \\
\hline ¿ & & & & & & & & & & & 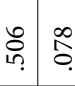 & $\begin{array}{l}\infty \\
\vdots \\
\vdots\end{array}$ & & & & & 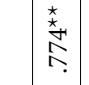 & $\vec{\sigma}$. & $\sharp$ & & 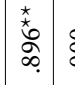 & 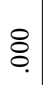 & 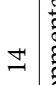 \\
\hline :ि & & & & & & & & 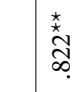 & ț. & ○ & 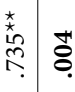 & 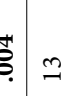 & \begin{tabular}{|l|}
\multirow{2}{*}{} \\
0 \\
0
\end{tabular} & $\tilde{\Xi}$ & 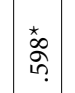 & ठే. & \pm & & 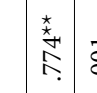 & $\vec{\Xi}$ & 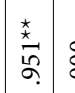 & 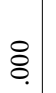 & 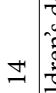 \\
\hline ڤ & \begin{tabular}{|l|}
$*$ \\
$\overrightarrow{7}$ \\
$\stackrel{7}{1}$ \\
$i$
\end{tabular} & రి. & $\infty$ & & & ก) & $\vec{b}$ & $\wedge$ & & & . & 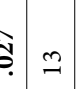 & 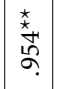 & ¿ & & & 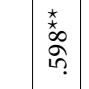 & $\begin{array}{lll}\overparen{\delta} & \pm \\
\end{array}$ & $\#$ & & 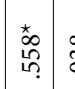 & 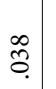 & $\Xi$ \\
\hline ถี & 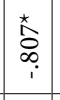 & $\begin{array}{l}0 \\
\stackrel{0}{0} .\end{array}$ & $\infty$ & & & & & & & & . & $\stackrel{2}{c}$ & & & 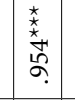 & ¿ & 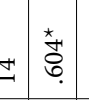 & $\tilde{\Xi}$. & $\ddot{H}$ & & 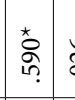 & ర్రి & \pm \\
\hline 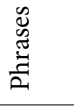 & & & & & & & & & & & 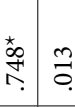 & $\begin{array}{ll}n \\
0\end{array}$ & & & & & & & & & & & \\
\hline 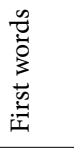 & & & & & & & & & & & & & त్ర & $\underset{\delta}{\tilde{\delta}}=$ & 童 & $\hat{\tilde{o}}$ & 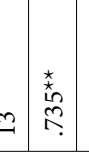 & 苛 $=$ & a & & & $\begin{array}{l}\infty \\
\stackrel{0}{0}\end{array}$ & 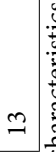 \\
\hline 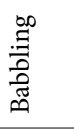 & & & & & & & & & & & 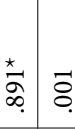 & 5 & & & & & 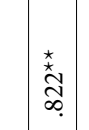 & $\stackrel{t}{0}$ & a & & 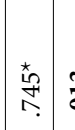 & $\stackrel{m}{a}$ & 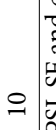 \\
\hline $\begin{array}{l}\text { 芯 } \\
\text { 范 } \\
3\end{array}$ & 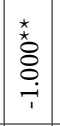 & 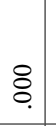 & $m$ & & & & & & & & 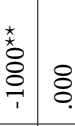 & s. & & & & & & & & & & & \\
\hline 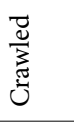 & & & & & & & & & & & & & & & & & & & & & & & \\
\hline 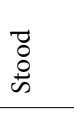 & & & & & & & & & & & & & 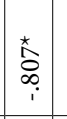 & \begin{tabular}{|l|l} 
& \\
& 0
\end{tabular} & 萧 & 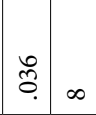 & $\infty$ & & & & & & \\
\hline $\overrightarrow{\tilde{\omega}}$ & & & & & & 离 & ڤ & $m$ & & & & & & & & & & & & & & & \\
\hline & 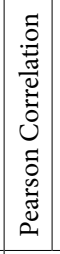 & 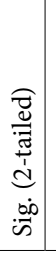 & & 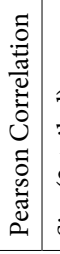 & 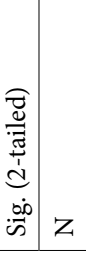 & 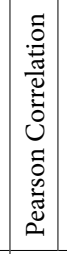 & 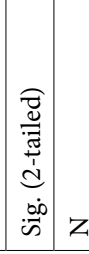 & 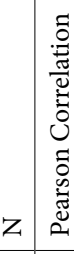 & 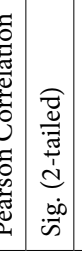 & $\mathrm{z}$ & 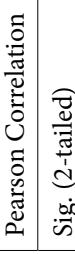 & 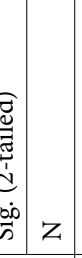 & 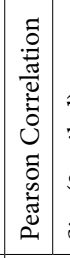 & 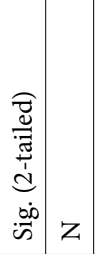 & 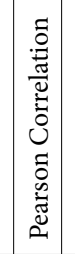 & 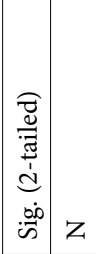 & 乙) & 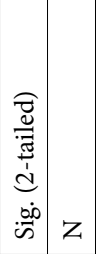 & 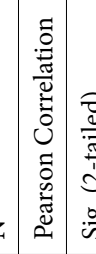 & 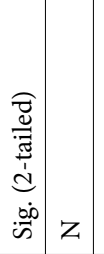 & 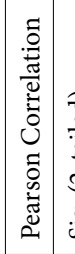 & 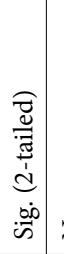 & $\mathrm{z}$ \\
\hline & $\begin{array}{l}\vec{z} \\
\stackrel{0}{0} \\
\dot{\omega}\end{array}$ & & & 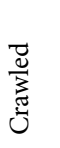 & & 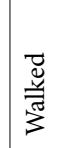 & & 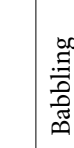 & لَّ & & 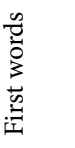 & & 纤 & & $\hat{\mathrm{a}}$ & & 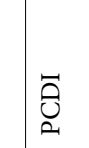 & & ü & & 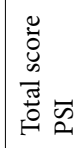 & & \\
\hline
\end{tabular}


Citation: Paraskevi E, Yannis S, Vassiliki S, Victoria Z (2020) Parental Stress in Cases of Children 'At Risk' for Specific Learning Disorder: A Pilot Study. Int J Psychol Behav Anal 6: 170. doi: https://doi.org/10.15344/2455-3867/2020/170

Page 5 of 6

\section{Discussion}

The aim of this pilot study was to investigate the levels of stress in parents whose children were early diagnosed 'at risk' for SLD. To our knowledge, no previous study has tested the psychological state of parents of children being diagnosed 'at risk' for SLD. Thus, the findings derived from the present pilot study could be considered as interesting, as they tend to contribute to a discussion of the potential interactions between early diagnosis of SLD and increased parental stress levels.

Managing and coping with the multilevel disabilities that they are expected to face, parents of children with learning disabilities inevitably experience a difficult situation, which affect both their daily and personal lives, in all dimensions. Consequently, it is expected that this situation has a significant impact on the upbringing of the child. As it can be seen, managing stress experienced by parents and combating their fear of social outcry and isolation are factors that could contribute positively to parents' psychological well-being, both directly and indirectly for themselves and their children, as they will be able to offer the best possible for them.

Considering this pattern of results, the findings derived, answering the research questions posed, could be interpreted as follows:

Answering the first question, we tried to examine whether demographic characteristics, such as marital status, educational level, and occupational status affect the parents' performance in the subscales of the Parental Stress Index. In contrast with findings of other researches [24], the findings of the present pilot study represented a statistically significant association of parents' (represented by mothers in our study) total parental stress score only with occupational status and not with other studied demographic characteristics. A plausible explanation for this finding is that there is a strong bidirectional relationship between the problems that the mothers meet at work (employment stress) with the difficulties that their children face, and vice versa. These two negative conditions seem to affect one another having as a result the increase of parents' stress.

Answering the second question, we sought to investigate whether parents exhibit parental stress that is associated with the manifestation of their children's disabilities. Based on the research objectives set out above, results show that overall parental stress levels were high in this sample, but without exceeding the 9.0-point barrier above which values are considered as pathological.

Concerning the other subscales of parental stress (other than total stress), it also appears that the highest values are reported in the subscales "Parental Distress Score" (PD) and "Difficult Child" (DC), which is probably interpreted by the number of undesirable behaviors that occur in cases of children with SLD.

These findings are in line with those of Woolfson \& Grant's (2006) [23] research, in which a strong correlation and proportionality were observed in the occurrence of adverse behaviors and parental anxiety, as parents who somehow succeed in managing these behaviors recorded quite lower levels of stress. Similarly, these findings confirm Bonifacci's et al. (2014) [24] and Karande's et al. (2009) [25] findings suggesting that mothers of children with specific learning disabilities exhibited increased levels of parental distress.

Interestingly, these findings seem to be consistent with those supporting that parents of children with developmental disorders experience higher levels of anxiety, compared to parents of children with other medical problems, as Pipp-Siegel et al. (2002) [26] argued, regarding parents of hearing-impaired children.

Similarly, Begum \& Desai's (2010) [27] study, which investigated the mental health of mothers of children with cerebral palsy compared to those of mothers of typical developmental children, found that the former had elevated levels of depression and anxiety compared to the latter.

Finally, the third question helped us determine whether and to what extent the parents' stress is affected by the degree of readiness with which their children acquire specific developmental skills, with regard to the occurrence of SLD. As it was observed, subcategories of the PSISF, such as DR, PD, PCDI, and Total Score PSI were highly correlated with the skills of standing, babbling, and saying first words. Similarly, all the developmental skills were significantly correlated with each other, indicating that particular domains of the child's development and, consequently, any problem related to them can, indeed, affect all the categories of the parents' expression of stress.

In addition, these findings do merit consideration, as, initially they corroborate the aspect that children 'at risk' of SLD meet difficulties in a wide range of skills under combined interactions between them [28]. Secondly, they stress the necessity of identifying (although this is not always easy for the children or their families) as early as possible the above difficulties for effective interventions to be applied without a delay [29].

Undoubtedly, the present pilot study includes both strengths and limitations. We strongly believe that the findings derived from the current pilot research could highlight the necessity for future research in such an important issue as the psychological state of parents whose children have been early diagnosed 'at risk' for SLD.

However, further studies are needed to extend the current results, taking into consideration limitations, as follows:

1. The sample number of this survey is small, as it consisted of 21 participants. Therefore, no generalized conclusions can be drawn in a safe manner. However, the results of the survey are encouraging, as they highlight the need for future research with a larger number of participants.

2. The results obtained were essentially a record of the present situation, as it was not possible to compare them with the situation of the parents after the completion of the treatment program.

3. In addition, it was not possible to correlate the results of the questionnaires with a significant variable, that of the time from diagnosis to interview, as this duration for all participants exceeded one year, a fact which excludes the possibility to study the period immediately after the diagnosis, which is, according to the literature review, the period during which parental anxiety shows the highest rates.

\section{Conclusions}

To conclude, two main aspects emerged from the present pilot study: (a) research operations carried out regarding the needs of the child 'at risk' for SLD, parental distress, and parent-child dysfunctional interactions contribute to highlight all possible situations that impede the functionality of the parents [30], and (b) the interpretation 
Citation: Paraskevi E, Yannis S, Vassiliki S, Victoria Z (2020) Parental Stress in Cases of Children 'At Risk' for Specific Learning Disorder: A Pilot Study. Int J Psychol Behav Anal 6: 170. doi: https://doi.org/10.15344/2455-3867/2020/170

Page 6 of 6

of adequate parenting stress measures leads to the adjustment of appropriate treatment of both the parenting stress and the children's specific learning difficulties [31].

\section{Competing Interests}

The authors declare that they have no competing interests.

\section{Acknowledgements}

Our particular thanks are due to the parents who agreed to participate in this survey.

\section{References}

1. Kirk SA, Bateman B (1962) Diagnosis and remediation of learning disabilities. Exceptional Children 29: 73-78.

2. Kalyva E, Agaliotis I (2009) Can social stories enhance the interpersonal conflict resolution skills of children with LD? Research in Developmental Disabilities 30: 192-202.

3. Hammill DD (1990) On defining learning disabilities: An emerging consensus. J Learn Disabil 23: 74-84.

4. Kavale KA, Spaulding LS, Beam AP (2009) A time to define: Making the specific learning disability definition prescribe specific learning disability. Learning Disability Quarterly 32: 39-48.

5. American Psychiatric Association (2013) Diagnostic and statistical manual of mental disorders (5th edition).

6. Craig F, Operto FF, De Giacomo A, Margari L, Frolli A, et al. (2016) Parenting stress among parents of children with neurodevelopmental disorders. Psychiatry Research 242: 121-129.

7. Minnes PM (1988) Family stress associated with a developmentally handicapped child. International Review of Research in Mental Retardation 15: 195-226.

8. Davis NO, Carter AS (2008) Parenting stress in mothers and fathers of toddlers with autism spectrum disorders: Associations with child characteristics. J Autism Dev Disord 38: 1278-1291.

9. Abidin RR (1995) Parenting Stress Index. Professional manual (3rd edition) Odessa, FL: Psychological Assessment Resources.

10. Ainbinder JG, Blanchard LW, Singer GH, Sullivan ME, Powers LK, et al. (1998) A qualitative study of parent to parent support for parents of children with special needs. J Pediatr Psychol 23: 99-109.

11. Heaman DJ (1995) Perceived stressors and coping strategies of parents who have children with developmental disabilities: a comparison of mothers with fathers. J Pediatr Nurs 10: 311-320.

12. Kypriotakis M, Frangogianni ME (2010) Family in the context of early support. In: Kornilaki AN, Kypriotakis MA \& Manolitsis G (Ed) Early Intervention: Interdisciplinary Theory Field, Athens.

13. Bella GP, Garcia MC, Spadari-Bratfisch RC (2011) Salivary cortisol, stress, and health in primary caregivers (mothers) of children with cerebral palsy. Psychoneuroendocrinology 36: 834-842.

14. King S, Teplicky R, King G, Rosenbaum P (2004) Family-centered service for children with cerebral palsy and their families: a review of the literature. Semin Pediatr Neurol 11: 78-86.

15. Wang P, Michaels CA, Day MS (2011) Stresses and coping strategies of Chinese families with children with autism and other developmental disabilities. J Autism Dev Disord 41: 783-795.

16. Zakopoulou V, Siafaka V, Tziakis N, Boukouvala M, Apostolidou M, et al. (2017) The effectiveness of individual diagnostic profiles in both the construction and application of suited intervention models in infants at risk of specific developmental dyslexia. Proceedings of the 20th Euro Congress of Psychiatrists and Psychologists.

17. Moll K, Thompson PA, Mikulajova M, Jagercikova J, Kucharska A, et al (2016) Precursors of Reading Difficulties in Czech and Slovak Children AtRisk of Dyslexia. Dyslexia 22: 120-136.

18. Mills-Koonce WR, Appleyard K, Barnett M, Deng M, Putallaz M, et al. (2011) Adult attachment style and stress as risk factors for early maternal sensitivity and negativity. Infant Ment Health J 32: 277-285.
19. Quittner AL, Barker DH, Cruz I, Snell C, Grimley ME, et al. (2010) Parenting stress among parents of deaf and hearing children: associations with language delays and behavior problems. Parent Sci Pract 10: 136-155.

20. Keen D, Couzens D, Muspratt S, Rodger S (2010) The effects of a parentfocused intervention for children with a recent diagnosis of autism spectrum disorder on parenting stress and competence. Research in Autism Spectrum Disorders 4: 229-241.

21. Esposito M, Marotta R, Roccella M, Gallai B, Parisi L, et al. (2014) Pediatric neurofibromatosis 1 and parental stress: a multicenter study. Neuropsychiatr Dis Treat 1: 141-146.

22. Lese E (2013) Clinical Genetic Assessment and Developmental Examination of Children Born with Preimplantation Genetic Diagnosis: Assessment of Parental Anxiety (Doctoral Dissertation, National and Kapodistrian University of Athens (NERC). School of Health Sciences. Department of Medical Medicine.

23. Woolfson L, Grant E (2006) Authoritative parenting and parental stress inparents of pre-school and older children with developmental disabilities. Child Care Health Dev 32: 177-184.

24. Bonifacci P, Montuschi M, Lami L, Snowling MJ (2014) Parents of children with dyslexia: Cognitive, emotional and behavioural profile. Dyslexia 20: 175-190.

25. Karande S, Kumbhare N, Kulkarni M, Shah N (2009) Anxiety levels in mothers of children with specific learning disability. J Postgrad Med 55: 165-170.

26. Pipp-Siegel S, Sedey AL, Yoshinaga-Itano C (2002) Predictors of parental stress in mothers of young children with hearing loss. Journal of Deaf Studies and Deaf Education 7: 1-17.

27. Begum R, Desai O (2010) A comparative study to evaluate psychological status of mothers of children with cerebral palsy and mothers of normal children. The Indian Journal of Occupational Therapy 42: 3-9.

28. Elliott JG, Grigorenko EL (2014) The dyslexia debate. Cambridge University Press.

29. Pennington BF, Santerre-Lemmon L, Rosenberg J, MacDonald B, Boada R, et al. (2012) Individual prediction of dyslexia by single versus multiple deficit models. J Abnorm Psychol 121: 212-224

30. Bonifacci P, Storti M, Tobia V, Suardi A (2016) Specific learning disorders: A look inside children's and parents' psychological well-being and relationships. J Learn Disabil 49: 532-545.

31. Holly LE, Fenley AR, Kritikos TK, Merson RA, Abidin RR, et al. (2019) Evidence-base update for parenting stress measures in clinical samples. J Clin Child Adolesc Psychol 48: 685-705. 